\title{
A PROTEÇÃO CONSTITUCIONAL AO MEIO AMBIENTE E A RETÓRICA DO DESENVOLVIMENTO: O CASO DA USINA HIDRELÉTRICA DE BELO MONTE
}

\author{
Lara Santos Zangerolame Taroco ${ }^{1}$
}

\section{RESUMO}

Este estudo analisa os discursos proferidos por diferentes autoridades durante o processo idealização e licenciamento ambiental da UHE Belo Monte, considerando as repercussões teóricas do termo desenvolvimento e da retórica. O projeto da Usina Hidrelétrica de Belo Monte, prevista para ser a terceira maior hidrelétrica do mundo, é perpassado por uma série de controvérsias e conflitos. É em razão de tais controvérsias, e contando com as contribuições da retórica, em sua acepção analítica e estratégica, que o presente estudo pretende analisar o emprego do termo desenvolvimento, tão presente nos pronunciamentos, pode ser empregado como artifício da retórica estratégica.

Palavras-chave: Desenvolvimento; Retórica; Usina Hidrelétrica de Belo Monte.

\section{THE CONSTITUCIONAL PROTECTION OF THE ENVIRONMENT AND THE RHETORIC OF THE DEVELOPMENT: THE CASE OF BELO MONTE'S HYDROELECTRIC PLANTS}

\begin{abstract}
This study analyzes the speeches made by different authorities during the process of environmental licensing of HPP Belo Monte, considering the repercussions of the term development and rhetoric. The Belo Monte Hydroelectric Plant project, expected to be the third largest hydroelectric plant in the world, is permeated by a series of controversies and conflicts. It is because of such controversies, and relying on the contributions of rhetoric, in its analytical and strategic sense, that the present study aims to analyze the use of the term development, so present in the pronouncements, can be used as a device of strategic rhetoric.
\end{abstract}

Keywords: Development; Rethoric; Belo Monte's Hydroelectric Plant.

\section{INTRODUÇÃO}

A idealização da Usina Hidrelétrica de Belo Monte ocorreu durante o período ditatorial brasileiro, em 1975, com o início dos Estudos de Inventário Hidrelétrico da Bacia Hidrográfica do Rio Xingu. As conclusões desses estudos foram divulgadas no Plano 2010 -

\footnotetext{
${ }^{1}$ Doutoranda em Direito Público pela Universidade do Vale do Rio dos Sinos - UNISINOS (bolsista Capes/PROEX). Mestre em Direito pela Faculdade de Direito de Vitória - FDV. E-mail: larasantosz@hotmail.com
} 
Plano Nacional de Energia Elétrica 1987/2010, as quais destacaram que: “pela sua dimensão, o aproveitamento do Rio Xingu se constituirá, possivelmente, no maior projeto nacional no final deste século e começo do próximo" (MORETTO, 2012, p.56), fazendo referência a então Usina Kararaô - que hoje passou a ser denominada de Belo Monte - como a melhor opção para iniciar a integração das usinas do Rio Xingu ao Sistema Interligado Brasileiro.

A realização de uma obra de infraestrutura de grande porte como essa, localizada na Bacia do Rio Xingu, no Pará, tem suscitado acirrados conflitos de interesses que tomaram enormes proporções a ponto de repercutir inclusive na esfera internacional. Nesse sentido, a partir das contribuições da retórica, tanto na concepção estratégica como analítica, o intuito do presente estudo é analisar os discursos proferidos por diferentes autoridades no curso desse conturbado processo de idealização e licenciamento ambiental da usina de Belo Monte, com vistas a identificar como se dá a legitimação ou não do projeto.

Entretanto, antes de adentrar propriamente à análise dos pronunciamentos, a ser promovida a partir das contribuições da retórica analítica, cumpre perquirir as origens etimológicas do termo desenvolvimento, bem como sua abordagem a partir de algumas matrizes teóricas. Esse exercício retórico analítico é fundamental para compreender a multiplicidade de relatos possíveis a respeito deste vocábulo, o que só qualifica sua complexidade e igualmente evidencia a prevalência de um relato vencedor, em detrimento de tantos outros vencidos.

Por isso, sem pretensão de esgotamento são aqui apresentados alguns relatos possíveis, perspectivas a respeito do desenvolvimento. Isso, a partir da matriz do darwinismo, que remonta a origem e os primeiros usos do termo; da economia, talvez a seara que mais se apropriou do desenvolvimento, estabelecendo uma relação de quase identidade, isto é, quando se fala de desenvolvimento a associação convencional é com o desenvolvimento econômico.

Tudo isso com vistas a realizar a análise conjunta de alguns discursos proferido por diferentes autoridades, no que se refere ao longo processo de controvérsias envolvendo a usina hidrelétrica de Belo Monte, para então analisar como o termo "desenvolvimento", tão presente nos pronunciamentos, pode ser empregado como artifício da retórica estratégica e quais os caminhos escolhidos para tanto.

\section{A TERMINOLOGIA E OS FUNDAMENTOS DA RETÓRICA MATERIAL, ESTRATÉGICA E ANALÍTICA}


A conhecida curiosidade de Alice ao perseguir o apressado coelho branco de olhos corde-rosa a fez cair em um poço, tão profundo que a menina teve tempo suficiente para olhar ao redor enquanto caía e para se perguntar o que iria acontecer a seguir. Durante a queda incessante, Alice tentou olhar para baixo e descobrir onde ia chegar, mas estava escuro demais para ver o fim (CARROLL, 2014). Mesmo assim a menina ainda cogitou: "devo estar chegando perto do centro da Terra", e logo concluiu que, pelo desespero do momento, não era hora de demonstrar os conhecimentos adquiridos na escola. Em seguida, Alice ainda emenda: “sim, é mais ou menos essa distância..., mas aí eu me pergunto em que latitude ou longitude?" (CARROLL, 2014, p.16), e o narrador observa: "Alice não tinha a menor ideia do que era latitude, nem longitude, mas achava que eram palavras muito imponentes para dizer" (CARROLL, 2014, p.16).

A obra de Lewis Carroll, "Alice no País das Maravilhas", é permeada por alegorias, reflexões constates sobre o novo mundo descoberto por Alice e indagações complexas da personagem, como: “quem eu sou?” ou “para onde vamos?”. O trecho destacado é pertinente para o presente estudo, pois exemplifica como as palavras muitas vezes são utilizadas como artifícios ou meramente para ornar e atribuir impacto a dado discurso.

Neste ponto, cabe mencionar que a retórica, de forma equivocada é por vezes concebida exclusivamente como "ornamento e estética para influir na opinião dos incautos" (ADEODATO, 2008, p.56). Entretanto, em que pese a relevância desta função, a complexidade da retórica transcende a seleção de "palavras imponentes para dizer", opção adotada por Alice. Para além disso, a retórica também opera "como instrumento para situar o ser humano de modo mais adequado no mundo, tanto no que concerne ao conhecimento quanto naquilo que diz respeito ao relacionamento com os demais seres humanos" (ADEODATO, 2008, p.57-58), tanto por isso consiste em base teórica da presente análise.

Em função disso, cumpre abordar, a partir das contribuições da obra de João Maurício Adeodato, a origem da retórica, os principais componentes de sua terminologia de bases sofistas e aristotélicas, bem como os conceitos de retórica material, retórica prática, ou estratégica, e a retórica analítica. No que concerne à origem, a retórica emerge vinculada à sofistica, e em razão disso agrega consigo certas resistências, provenientes desta relação inicial. A afetação da retórica ocorre em virtude dos preconceitos e controvérsias da sofistica, os quais acabam por transportar-se também para a retórica. Como observa Adeodato (2007, p.298): 


\begin{abstract}
O fato é que poucos círculos filosóficos causam tanto debate e controvérsia como o da sofistica. Seus defensores ora são vistos como politicamente de esquerda, ora como de direita, desde os sofistas clássicos, que se contrapunham a Sócrates, Platão e Aristóteles, até os céticos contemporâneos. São, por outro lado, considerados sintoma e mesmo causa da decadência da polis grega e, por outro lado, progressistas, modernos, até iluministas. Relativistas, niilistas, agnósticos individualistas, céticos e positivistas são alguns dos epítetos aplicados aos sofistas, todos com fundamentos.
\end{abstract}

Assim sendo, os fundamentos iniciais entrelaçam-se as bases sofisticas e também às contribuições aristotélicas da retórica da Grécia antiga. Dentre as terminologias utilizadas, cabe especial destaque as provas da argumentação persuasiva oferecidas por meio do discurso, presentes na Retórica de Aristóteles, quais sejam: ethos, pathos e logos. Estes termos compunham formas de persuadir por intermédio da comunicação e da apresentação dos oradores (DÜRING, 1990), restando importante o alerta de que estas expressões com o transcurso do tempo sofrem com "o grau de porosidade linguística das palavras; há intersecções, diferentes traduções ou simplesmente confusões entre os termos" (ADEODATO, 2008, p.60).

O ethos relaciona-se com o caráter do orador, sendo que tal caráter é resultado do hábito, "que se percebe na aparência, nos traços, nas características, no olhar, no porte" (ADEODATO, 2008, p.61). É, portanto, o destaque dado para quem está falando, a importância que se confere ao orador por ser quem é. Nesse ponto, cabe destacar que o caráter do orador não se desvincula do discurso, ao passo que o ethos é construído também por meio do discurso. Já o pathos volta-se para a preocupação em "provocar no auditório certo estado de espírito" (ADEODATO, 2008, p.60), sendo que o vocábulo significa paixão, emoção, sentimento.

Nesta medida, enquanto o ethos relaciona-se com a figura do orador, o pathos vinculase ao ouvinte, que pode vir a alterar suas opiniões em razão de certas emoções provocadas, as quais retiram o ouvinte de seu estado habitual. Interessante destacar a abordagem de Perelman (1998), por exemplo, concernida em prover a análise dos auditórios para os quais são proferidos os discursos, com vistas a selecionar as teses apropriadas, a fim de obter aceitação. Essa proposta resgata, em grande parte, o estudo do pathos já desenvolvidos por Aristóteles, sendo que, como destaca Adeodato (2008, p.63):

A importância dada ao pathos pelos oradores parece ter sido muito grande na retórica sofística ao tempo de Aristóteles, pois ele faz críticas aos discursos excessivamente ou exclusivamente circunscritos ao pathos. Mesmo assim, em sua ética, apesar de os sentimentos serem considerados irracionais, Aristóteles destaca a 
importância do pathos e vê uma relação estreita entre pathos e ethos, pois os afetos precisam ser controlados pela virtude do caráter e alcançar um meio-termo desejável racionalmente.

No que concerne ao $\log o s$, apesar das traduções, que o identificam com razão ou ciência, este termo não assumia na Grécia antiga a relação com a razão e a ciência lógica atribuída pela modernidade, tanto que "originalmente parece ter significado de linguagem" (ADEODATO, 2008, p.63). Cumpre, portando, ressaltar que o sentido de logos ora adotado o concebe como "linguagem em sentido performático, com todas as suas estratégias e matrizes, não designa apenas o sistema de regras dirigentes do pensamento" (ADEODATO, 2008, p.63). Assim, para análise das três provas retóricas, o logos se identifica pelas palavras que compõem o discurso ora proferido, o discurso propriamente dito.

Além destes fundamentos, que remontam a origem retórica e serão fundamentais para a análise de discurso ora proposta, pertine para o presente estudo tratar também da relação da distinção entre retórica material, retórica prática ou estratégica e retórica analítica, proposta por Ottmar Ballaweg e desenvolvida neste texto a partir das contribuições da obra de João Maurício Adeodato. A retórica material pode ser compreendida como "a maneira pela qual os seres humanos efetivamente se comunicam, suas artes e técnicas sobre como conduzir-se diante dos demais, tecendo o próprio ambiente em que acontece a comunicação" (ADEODATO, 2008, p.64), sendo essa uma repercussão natural da condição humana, ao passo que acontece mesmo de forma irreflexiva, já que os seres humanos dependem necessariamente da linguagem para estruturação de seus relatos sobre o mundo.

A elaboração desses relatos ocorre intersubjetivamente e diferente da proposta cartesiana, a experiência subjetiva não pode isolar-se das influências do mundo exterior, com o intuito de retirar unicamente dessa experiência interna os elementos para a construção de sentido (GRODIN, 1999, p.155). A comunicação se estabelece intersubjetivamente por meio do compartilhamento dos sentidos atribuídos ao mundo (ECO, 2004, p.14), portanto, a própria realidade é retórica (ADEODATO, 2007, p.329), sendo que essas atribuições, como são produzidas por meio da linguagem, carregam consigo a porosidade, a ambiguidade e os desacordos decorrentes desta condição.

Ademais, essa comunicação está sujeita ao controle público da linguagem, subordinadas a verificação de correspondência do sentido ora atribuído, sendo que tais “controles são condicionados, temporários, autopoiéticos e circunstanciais; quanto mais complexo o meio social, mais se acentua esse caráter mutante e mais difícil estuda-lo" 
(ADEODATO, 2007, p.309). Nesse contexto, a retórica material volta-se para aos fatos, enquanto construções intersubjetivas, relatos provenientes da atividade comunicativa, que constitui a própria condição antropológica da retórica, sendo que neste cenário o que se estabelece é a incapacidade de transcender os relatos, que pela linguagem elaboram visões de mundo.

A retórica prática ou estratégica, por sua vez, não se desdobra de forma natural, como ocorre com a material. Há aqui atividade reflexiva, ao passo que também constitui um primeiro grau da meta-retórica, já que se estabelece sobre a retórica material, pois mediante os elementos desta opera para reconstruí-la e intervir sobre ela (ADEODATO, 2008). Se a retórica material trata dos fatos, a atividade da retórica estratégica estabelece discursos, que com base em teorias adotam estratégias para intervir sobre os fatos, com vistas a estabelecer versos fixas sobre estes fatos. Disso decorre elaborações de visões de mundo, que com base em teorias interferem na realidade, narrando a à luz de determinada lente teórica para estrategicamente obter sucesso, instituindo-se como o relato correto. Por isso, pode ser compreendida como uma "metodologia da retórica material" (ADEODATO, 2008, p.73), que adota métodos para se chegar a dado efeito.

Por fim, a retórica analítica visa adotar uma perspectiva descritiva, abstraindo referências valorativas para então poder analisar da forma mais distanciada possível as diversas influências que as metodologias exercem sobre os discursos. Em razão de tais características pode ser identificada como metalinguagem, pois objetiva a "observação das retóricas material e estratégica, sem o objetivo de influir sobre elas" (ADEODATO, 2008, p.74), promovendo, dentro das possibilidades, a mais ampla análise dos elementos em questão. A partir dessa construção, restam evidentes os equívocos cometidos em identificar a retórica somente com a indução do discurso em favor ou desfavor de certo posicionamento, atribuindo a essa complexa abordagem apenas a função de influenciar o ouvinte ou ainda, como Alice, apenas como técnica de seleção das "palavras muito imponentes para se dizer". Tal reducionismo traz à ribalta exclusivamente a retórica em sua acepção estratégica, olvidando o todo, composto pela retórica material e analítica.

Dessa forma, as terminologias e os fundamentos retóricos ora apresentados são essenciais para a abordagem pretendida pelo presente estudo. Tendo em vista, que é por intermédio do exame analítico de discursos, que se objetiva identificar a utilização estratégica do termo "desenvolvimento", nos pronunciamentos de diferentes autoridades durante o 
controverso processo de idealização, construção e licenciamento ambiental da usina hidroelétrica de Belo Monte.

\section{O DESENVOLVIMENTO COMO ARTIFÍCIO DA RETÓRICA ESTRATÉGICA: DO ETIMOLÓGICO AO AXIOLÓGICO}

A etimologia da palavra "desenvolvimento", que tem como origem o latim, remonta a união do núcleo "volver" - do latim "volvere" -, que significa reverter, virar, rolar, fazer girar, com o prefixo de negação ou ausência "des", incrementado com o signo "en" - do latim "in" - cujo significado é movimento para dentro e, por fim, pelo sufixo "mento", representativo de ação (BALDINGER, 1998). Em uma análise fragmentada do radical "volvere" com o componente "in" se extrai "involvere", base da palavra envolver, construção que auxilia a sustentar o sentido de desenvolvimento como desenrolar, que com a ação do sufixo "mento" representa a ação de fazer algo desenrolar, impulso que se move para o sentido oposto de "movimento para dentro", em razão do prefixo de negação ou ausência: "des" (JATOWT; DUH, 2014).

Essa investida - ou esse "desenvolvimento" - pretende permitir o aparecimento de algo que estava tolhido e encontra nos dicionários sinônimos: como crescimento, progresso e melhoria (FERREIRA, 2009), que permitem incrementar ou deturpar a adequação de sentido da palavra quando da sua aplicação, ao passo que são termos próximos, mas não idênticos. Então, o que poderia ser caracterizado como o simples desabrochar passa a assumir outras conotações, que, por vezes, fogem ao radical etimológico e são incrementadas por uma carga axiológica, em geral, positiva. O desenvolvimento aliado ao progresso e ao crescimento constituem três vocábulos cujos sentidos são aprisionados por muitas teorias à uma carga axiológica necessariamente positiva. Esse atributo é posto como verdade, o que implica na afirmação incontroversa de que todo desenvolvimento, progresso e crescimento são bons.

A imposição e consequente aceitação desse relato, aparentemente vencedor, não condiz com uma postura retórica, a não ser que seja para manejar essa suposta verdade de forma estratégica, para fortalecer certos argumentos. No mais, cabe à postura retórica analítica refletir e questionar essa verdade posta, até mesmo com vistas a renovar a clássica oposição em relação a inclinações ontológicas (ADEODATO, 2005), com vistas a elucidar também outros relatos possíveis. Em consonância com essa perspectiva, cumpre pontuar que o transcurso do tempo e o uso por diferentes campos de atuação fez com que a palavra 
desenvolvimento aglutinasse uma série de sentidos, tanto a favor, quanto para além de uma carga axiológica necessariamente positiva, a depender da luz direcionada por cada teoria.

No campo da biologia, principalmente a partir das contribuições de Lamarck e Darwin, o desenvolvimento (ALMEIDA; FALCÃO, 2015) foi difundido associado com a proposta evolucionista darwiniana ou transformista lamarckiana, empregado como processo de evolução dos seres vivos para alcance de potencialidades genéticas, seja em razão da aleatoriedade da seleção natural ou de forma teleológica e determinada (BUCKHARDT, 1970). Segundo as conclusões de Darwin, "um organismo se desenvolve à medida que progride em direção à sua maturidade biológica" (BUCKHARDT, 1970, p.56), sendo que essa abordagem teórica passou a ser transferida também para a vida em sociedade, o que deu origem, nas últimas décadas do século XVII ao darwinismo social (BLANC, 1994).

A aplicação da teoria da evolução das espécies às sociedades humanas repercutiu em asserções que consideravam a "sobrevivência dos mais aptos" (BLANC, 1994, p.97), conforme elucidou Herbert Spencer, em razão do melhor desenvolvimento no meio social, pautado sempre por uma frequente luta natural. As ramificações teóricas que decorreram do darwinismo social vincularam-se à eugenia e outras ideologias racistas, partidárias de um desenvolvimento genético construído mediante a seleção de certas características mais evoluídas e puras.

São as contribuições germânicas que introduzem pioneiramente a noção de desenvolvimento econômico, e é em razão das traduções que o conceito ingressa também no vocabulário econômico de língua inglesa. "A teoria do desenvolvimento econômico" Theorie der wirtschaftlichen Entwicklung -, de J. A. Schumpeter, que foi traduzida para o inglês somente a partir de 1934, já utilizava amplamente, em 1911, o conceito de Entwicklung para designar desenvolvimento, em alemão, língua original da publicação (NASAR, 2012).

Entretanto, o uso de Entwicklung pela literatura alemã, enquanto desenvolvimento associado a questão economia, remete primeiramente à obra "Capital", de Karl Marx, percursor responsável por dar a palavra desenvolvimento uma conotação especificamente econômica (ARNT, 1987). Além disso, inspirar o próprio Schumpeter (1951), que reconheceu essa influência, apesar de ambos abordarem conclusões diversas.

É de Marx (1998, p.222) a constatação de que "a burguesia não pode existir sem revolucionar constantemente os instrumentos de produção", o que repercute em um "vendaval 
criativo" ao mesmo tempo que também instaura um ambiente de constate ruptura, onde "tudo que é sólido desmancha no ar" (MARX, 1998, p.208). Nessa perspectiva o ideal de desenvolvimento é crucial no pensamento de Marx, sendo representado pelo aprimoramento dos meios de produção e pelo acúmulo de capital, objetivo central do modelo capitalista (BERMAN, 1986, p.96). Em que pese tais momentos iniciais, que fincam as bases do conceito de desenvolvimento, é no cenário pós-Segunda Guerra Mundial que surge a disciplina Economia do Desenvolvimento (MAGALHÃES, 2008), responsável por reunir diferentes economistas voltados para a construção de um arcabouço teórico que desse conta de analisar o desenvolvimento a partir de uma sociedade industrial, urbana, com novos atores e tanto por isso, complexa.

Nesse cenário, muitas escolas econômicas seguem considerando desenvolvimento como sinônimo de industrialização, sendo que desenvolver-se é também industrializar-se, por definição. Entendimento que para alguns teóricos, como Arrighi (1998, p.208), deve ser afastado, ao passo que a industrialização não representa um fim em si mesmo, é "mas como um meio na busca de riqueza, ou de poder, ou de bem-estar, ou de uma combinação disso" e não tem relação de identidade com o desenvolvimento. De forma mais incisiva, destaca Amartya Sem (2010, p.28), que uma concepção adequada de desenvolvimento "deve ir muito além da acumulação de riqueza e do crescimento do Produto Nacional Bruto e de outras variáveis relacionadas à renda. Sen desconsiderar a importância do crescimento econômico, precisamos enxergar muito além dele". A proposta de Sen, volta-se muito mais para os elementos humanos relacionados ao desenvolvimento, como a garantia de direitos, o consequente bem-estar e o aprimoramento das liberdades públicas.

O olhar para além do crescimento econômico implica na abertura de uma fresta, que pretende rachar a certeza proveniente de uma visão progressista da história e questionar a acepção econômica de desenvolvimento, ao avaliar as consequências desse modelo, historicamente fundado na busca pelo acúmulo de riquezas e no desenvolvimento como sinônimo de progresso. Essa são algumas luzes teóricas, que iluminam de ângulos diferentes a compreensão sobre o desenvolvimento, as quais carregam consigo, cada uma a sua maneira, o intuito de cintilar um caminho possível, por vezes ofuscando, para tanto, muitos outros. Mediante estas contribuições, cumpre analisar os discursos proferidos durante o processo de idealização, construção e licenciamento ambiental da usina hidroelétrica de Belo Monte, com 
vistas a identificar a manifestação estratégica de certas abordagens teóricas a respeito do desenvolvimento.

\section{OS IMPASSES DO "CASO DA USINA DE BELO MONTE" E A RETÓRICA ESTRATÉGICA: ANALÁLISE DO DISCURSO A PARTIR DO "DESENVOLVIMENTO"}

A elaboração de projetos interventivos na Amazônia, como política da ditadura militar, remonta período anterior a idealização da Usina Kararaô, futura Belo Monte, que representou nesse contexto, um dos maiores empreendimentos da proposta desenvolvimentista ditatorial. Em 1970, o então presidente do Brasil, general do Exército Emílio Garrastazu Médici, ressaltou a intenção de utilizar de forma eficaz os recursos da região, concebida como "uma terra sem homens". Nesse sentido, o enforque dado por Médici é de que:

\footnotetext{
Somente quem testemunhou no Nordeste a caminhada de milhões de brasileiros sem terra e, agora, vem à Amazônia contemplar essa paisagem de milhões de hectares ainda desaproveitados, pode sentir, em toda a sua crueza, o quadro vivo de nossa luta pelo desenvolvimento (...) aquilo que não se pode fazer devido à escassez de capital pode ser feito com um programa integrado de desenvolvimento, com um mínimo de recursos econômicos, capaz de gerar rapidamente a riqueza, para complementar, sem inflação, o esforço necessário à solução dos problemas.
}

A aplicação do termo desenvolvimento nesse contexto associa-se com as pretensões de crescimento econômico e progresso, típica dos slogans adotados pelo regime militar e que bem representam a vertente, exposta em capítulo anterior, que pretende esgotar o sentido de desenvolvimento no aspecto material, ou seja, de acumulação de recursos econômicos. $\mathrm{O}$ planejamento e consequente execução da obra foi marcado por forte oposição de grupos ambientalistas, que em fevereiro de 1989 reuniram-se com autoridades, dentre eles o então diretor e posterior presidente da Eletronorte (FLEURY; ALMEIDA, 2013), estatal responsável pelo projeto, José Antônio Muniz Lopes. Iconicamente, durante a exposição de Muniz Lopes sobre a construção da usina Kararaô, a índia Kayapó Tuíra, levantou-se da plateia e encostou a lâmina de seu facão no rosto do diretor da estatal em um gesto de advertência, expressando sua indignação.

A cena foi reproduzida em jornais de diversos países e tornou-se histórica. Na ocasião, Muniz Lopes anunciou que, por significar uma agressão cultural aos índios, a usina Kararâ̂ nome que é um grito de guerra Kayapó - receberia outro nome e não seriam mais adotados 
termos indígenas em usinas hidrelétricas (THÉRY, 2002). O evento foi encerrado com o lançamento da Campanha Nacional em Defesa dos Povos e da Floresta Amazônica, exigindo a revisão dos projetos de desenvolvimento da região e com a Declaração Indígena de Altamira. Contudo, continuou a tramitar por toda a década de 1990 e início dos anos 2000, entre órgãos de governo e sob protestos de movimentos sociais, o Relatório Final dos Estudos de Viabilidade do Aproveitamento Hidrelétrico de Belo Monte - agora rebatizada. Em março de 2002, sob o governo Fernando Henrique Cardoso, que vivenciou uma forte crise energética, foi publicada uma Resolução do Conselho Nacional de Política Energética.

A resolução criou um Grupo de Trabalho (GT) com o objetivo de estudar e apresentar um plano de viabilização para a implantação da Usina Hidrelétrica de Belo Monte (BRASIL, 2004). Este GT manifestava o declarado interesse do governo federal na usina, considerandoa uma obra estratégica para elevar a oferta de energia do país e um projeto estruturante do "Eixo de Desenvolvimento da Amazônia". Foram muitas as críticas em relação à adoção desses programas no governo FHC, conforme aponta Théry (2010, p.34):

O setor ambiental do governo encontrou-se então no meio de uma tempestade,
recebendo de um lado apoios, dentro e fora do país, e, de outro, fortes críticas.
Circulavam nas redes mundiais informações sobre os progressos e retrocessos dessa
política, e pressões permanentes eram exercidas sobre as ações governamentais.
Esperando que aparecessem elementos mais sólidos aos serviços das políticas de
conservação, essas pressões serviam para travar a implantação das infra-estruturas e
para reduzir os impactos. Contribuíam a este fim as ações do Ministério Público
federal ou dos estados, baseadas em leis que permitiam respaldar a ação popular, e
algumas obras de grande porte, como a hidrovia Araguaia-Tocantins, foram
embargadas.

O ano de 2002 foi marcado pelos protestos em relação a retomada do projeto da usina, sendo que os povos indígenas realizam novo encontro a fim de reafirmar a posição contrária à construção de Belo Monte. No mesmo ano, Fernando Henrique Cardoso afirma que a briga dos ambientalistas tem prejudicado o crescimento econômico do país: “[...] além do respeito ao meio ambiente, é preciso que haja também respeito às necessidades do povo brasileiro, para que a 'birra' entre os diferentes setores não prejudique as obras, porque elas representarão mais emprego.” (INSTITUTO SOCIOAMBIENTAL, 2012). Posteriormente, em 2012, quando já não mais ocupava a Presidência da República, Fernando Henrique Cardoso respondeu à um questionamento no Fórum Mundial de Sustentabilidade em Manaus sobre a construção da usina de Belo Monte: 
(...) eu não gosto dessas construções de barragens, mas tem que entender que um país como o nosso precisa de energia para se desenvolver, então precisamos ver de que maneira fazer isso. Em tese eu preferiria que não houvesse, mas é preciso ver qual a urgência de produzir energia, e qual a energia mais barata (INSTITUTO SOCIOAMBIENTAL, 2012).

O posicionamento só endossa a perspectiva que relaciona o desenvolvimento a acepção econômica, e ressalta as necessidades de consumo energético do país para justificar a proposta, estratégia que recorre ao público indefinido para sustentar-se, na medida em que se trata de uma ação que será benéfica para todos os brasileiros. A indefinição do termo "povo brasileiro" permite a indução de que se trata de uma política de governo benéfica para todos, mas que exclui de seu alcance semântico as comunidades indígenas e ribeirinhas diretamente afetadas pela construção.

Ainda no ano de 2002, a fim de fazer oposição ao então presidente da república, em plena campanha presidencial, Lula da Silva apresenta a Carta ao Povo Brasileiro (SILVA, 2012), documento que apresenta as diretrizes que seriam tomadas em seu governo. No texto, Lula sinaliza a necessidade de mudança e renovação para o país: “O Brasil quer mudar. Mudar para crescer, incluir, pacificar. Mudar para conquistar o desenvolvimento econômico que hoje não temos e a justiça social que tanto almejamos. Há em nosso país uma poderosa vontade popular de encerrar o atual ciclo econômico e político" (SILVA, 2012). Em setembro do mesmo ano, Lula da Silva lança um caderno temático de seu programa de governo, intitulado O Lugar da Amazônia no Desenvolvimento do Brasil. O documento menciona que dois projetos vinham sendo objeto de grandes debates na região Amazônica, respectivamente a UHE de Belo Monte e o de Gás de Urucu, e afirma que as obras de represamento de rios têm afetado a Bacia Amazônica, além de criticar as ações da Eletronorte.

\begin{abstract}
A matriz energética brasileira, que se apóia basicamente na hidroeletricidade, com megaobras de represamento de rios, tem afetado a Bacia Amazônica. A crise do setor energético de 2001 resultou da ausência de investimento no setor e também da falta de proteção dos mananciais e da má gestão da água. [...] Considerando as especificidades da Amazônia, o conhecimento fragmentado e insuficiente que se acumulou sobre as diversas formas de reação da natureza em relação ao represamento em suas bacias, não é recomendável a reprodução cega da receita de barragens que vem sendo colocada em prática pela Eletronorte (SILVA, 2012).
\end{abstract}

No mesmo mês, o Partido dos Trabalhadores (PT) lança outro caderno temático, denominado Compromisso com os Povos Indígenas do Brasil. O documento, elaborado com a participação de diversas lideranças indígenas, expôs a gestão da política indigenista do governo anterior qualificando-a como lamentável. A crítica recai, entre outras, às dificuldades 
do processo de demarcação de terras indígenas, a lentidão para a criação de um novo Estatuto das Sociedades Indígenas, e às precárias condições de funcionamento da Funai (FONTES, 2003).

No entanto, a partir de 2003, o projeto para a construção da Usina de Belo continua a ser uma proposta do governo federal para ampliar seu complexo energético, inserido posteriormente no PAC5 - Programa de Aceleração do Crescimento, lançado em 28 de janeiro de 2007. Assim sendo, pode-se dizer que a construção de hidrelétricas no Rio Xingu fez parte de uma herança que foi herdada pelo Governo Lula, que este prosseguiu ao dar encaminhamento de um projeto que, do ponto de vista ambiental e social, em nada diferia do governo anterior.

Nos anos seguintes, a contestação dos movimentos ambientalistas permanece, e o caso Belo Monte é levado à Comissão Interamericana de Direitos Humanos, em Washington, Estados Unidos, e também à Organização das Nações Unidas (ONU). É enviada uma carta denunciando a violação do direito de consulta livre, prévia e informada, previsto na Convenção 169 da Organização Internacional do Trabalho (OIT) e na Declaração da ONU sobre os Direitos dos Povos Indígenas, devido ao processo unilateral do licenciamento e sem consulta prévia do governo brasileiro sobre a Usina Belo Monte (BBC, 2011).

Em resposta, a Comissão Interamericana de Direitos Humanos (CIDH) da Organização dos Estados Americanos (OEA), em 2011, pede a paralisação do processo de licenciamento da Usina Hidrelétrica Belo Monte, no Rio Xingu (PA). O retorno do Brasil em relação a recomendação da OEA é que, nas palavras do Ministro das Relações Exteriores, Antonio Patriota: “O Brasil está dando um exemplo de desenvolvimento sustentável nessas áreas, tanto ambiental como a de respeito aos direitos indígenas, é injustificável e precipitadas as afirmações da OEA de que os povos indígenas estariam supostamente ameaçados pela construção de Belo Monte" (BONIN, 2011). E ainda ressaltou:

O governo brasileiro, sem minimizar a relevância do papel que desempenham os sistemas internacionais de proteção dos direitos humanos, recorda que o caráter de tais sistemas é subsidiário ou complementar, razão pela qual sua atuação somente se legitima na hipótese de falha dos recursos de jurisdição interna (BONIN, 2011).

Nesse cenário, a expressão “desenvolvimento sustentável”, tal qual empregada pelo Ministro das Relações Exteriores, assume um papel fundamental na elaboração do discurso estratégico. O surgimento da expressão remete aos trabalhos da Comissão Mundial sobre o Meio Ambiente e Desenvolvimento, também conhecida como Comissão Brundtland, que 
produziu o relatório "Nosso Futuro", entregue à Assembleia Geral das Nações Unidas em 1987. O referido relatório abordou a temática do desenvolvimento sustentável, que não deve ser compreendido como um "estado permanente de harmonia, mas um processo de mudança no qual a exploração dos recursos, a orientação dos investimentos, os rumos do desenvolvimento tecnológico e a mudança institucional estão de acordo com as necessidades atuais e futuras".

As dimensões do desenvolvimento sustentável, elaboradas em momento subsequente, evidenciam a concepção holística (OST, 1995) que deve ser atribuída ao desenvolvimento, que não pode pautar-se apenas para o cenário econômico, mas que também deve levar em consideração a questão social e ambiental. Em pese esse contexto de surgimento do termo desenvolvimento sustentável, o que se observa é a utilização estratégica desse conceito, com vistas a legitimar posições que ainda são pautadas no modelo de desenvolvimento como progresso e crescimento econômico. Sendo assim, mesmo quando as atividades em questão não demonstram qualquer correspondência com a proposta sustentável de desenvolvimento, esse conceito é manejado estrategicamente para evitar resistências e obter consensos, tal como ocorre no pronunciamento supracitado.

O maior ponto de controvérsia é o procedimento de licenciamento ambiental da usina: objeto de 12 das 20 ações jurídicas movidas pela Procuradoria da República do Ministério Público Federal no Pará contra o projeto de construção da hidrelétrica. São questionadas juridicamente desde a decisão de quem seria o órgão regulador do licenciamento (Ibama, órgão federal, ou a SEMA, órgão estadual), até cada uma das três licenças ambientais concedidas até o momento para o empreendimento (licença prévia, licença parcial de instalação e licença de instalação), opondo nos tribunais órgãos federais, como o Ministério Público Federal e a Advocacia Geral da União.

Os questionamentos ao procedimento de licenciamento ocorrem em razão do particular caminho percorrido pelo projeto de Belo Monte, diverso do que determina a legislação ambiental, bem como a Constituição. Cumpre destacar que o licenciamento ambiental é um procedimento do qual fazem parte o EIA - estudo de impacto ambiental -, o RIMA - relatório de impacto ambiental -, o RAIAS - relatório de ausência de impacto ambiental significativo e a licença ambiental propriamente dita.

Como bem se sabe o referido procedimento é um dos instrumentos da Política Nacional do Meio Ambiente, na forma do art. $9^{\circ}$, inciso IV, da Lei 6.938/81. O procedimento 
pode ser compreendido como complexo, na medida em que se desenvolve em três fases, não sendo composto apenas por um licença expedida em um momento único. Assim, as três fases que compõem o procedimento é a da licença prévia, concedida em momento inicial, sendo esta fase preliminar de organização e planejamento da atividade a ser desenvolvida pelo empreendimento. Nesta fase o empreendedor destaca a intencionalidade de promover dado projeto, sendo então elaborados os estudos de viabilidade do projeto, dentre eles o estudo de impacto ambiental. Mediante a analise, discussão e aprovação destes estudos preliminares, o órgão administrativo ambiental expede a licença prévia (MILARÉ, 1993).

O passo seguinte é composto pela licença de instalação, concedida na fase de elaboração do projeto executivo, no qual são postas prescrições de natureza técnica, capazes de compatibilizar a instalação do empreendimento com a proteção do meio ambiente (MILARÉ, 1995). Tais condicionantes são essenciais para o sistema que pretende viabilizar a proteção do meio ambiente, na medida em que, quando observadas, possibilitam a sustentabilidade do projeto, que além de atender as pretensões do empreendedor, também atende ao intuito de preservação ambiental.

Por fim, a licença de operação compõe a última etapa do procedimento, momento em que é autorizada a operação da atividade ou empreendimento, após a verificação do cumprimento das condicionantes constantes nas licenças anteriores. Nessa toada, resta claro a sucessividade das etapas do licenciamento, que devem ser observadas na ordem prevista em lei, a fim de assegurar o arcabouço protetivo pretendido pelo texto constitucional.

No caso de Belo Monte houve uma peculiaridade, na medida em que foi concedida uma "licença prévia de instalação" (ANTONAZ, 2009), modalidade que não encontra qualquer previsão legal. Uma vez que não houve o cumprimento de todas as condicionantes listadas na licença prévia - no total de 66 condicionantes - para que a emissão da licença de instalação inicial do empreendimento fosse concedida, foi "criada" essa nova modalidade de licença.

Além disso, mais de 10 ações judiciais foram propostas pelo Ministério Público Federal (MPF), dentre elas a Ação Civil Pública10 (ACP nº. 26161-70.2010.4.01.3903) para obrigar a realização de audiências públicas em todas as comunidades afetadas (INSTITUTO SOCIOAMBIENTAL, 2012). Nesta ação, o MPF argumenta que esse direito não foi concedido aos povos indígenas, o que representa uma grave violação os direitos humanos desses povos e a condução não sustentável do projeto de Belo Monte. 
Sustenta-se que, nas quatro audiências públicas realizadas sobre o projeto (ocorridas entre os dias 9 e 15 de setembro de 2009), não houve condições para a efetiva participação da população e dos grupos diretamente afetados. Vale ressaltar que a Bacia do Xingu é composta por 24 grupos éticos. Esse fato levou entidades da sociedade civil a proporem uma demanda na Comissão Interamericana de Proteção aos Direito Humanos (CIDH). Uma vez esgotados todos os meios judiciais internos e tendo sido alegada a violação de um direito ou liberdade protegido pela Convenção de Direitos Humanos, entidades civis recorreram à CIDH (ANTONAZ, 2009).

Esse cenário, agravado pela situação atípica de uma modalidade de licença ambiental inexistente na legislação - que já havia sido utilizada em outras situações, também para viabilização a condução de hidrelétricas (INSTITUTO SOCIOAMBIENTAL, 2012) suscitou uma série de protestos por parte da sociedade civil e o Ministério Público Federal entrou com um pedido de liminar para suspender essa licença e impedir que as obras fossem iniciadas. Em 3 de março de 2011, a liminar que impedia o início da construção do canteiro de obras de Belo Monte foi derrubada e a licença de instalação, concedida pelo IBAMA em janeiro de 2011, foi mantida.

No mesmo mês, José Antônio Muniz Lopes, então presidente da Eletrobras, conhecido por projetar e apoiar a obra da usina de Belo Monte, figura imortalizada ao longo desse processo de contestação, sobretudo, por ter protagonizado o simbólico episódio de revolta da índia Kayapó Tuíra em 1989, concedeu entrevista ao Jornal Estado de São Paulo. Na reportagem, ao comentar a revogação da liminar que impedia o início das obras, destacou: "o país perdeu por não ter feito Belo Monte antes". Ademais, também respondeu os seguintes questionamentos:

Se o projeto é tão bom, por que tanto problema no licenciamento?

MUNIZ: Todo mundo sempre é contra as hidrelétricas na Amazônia. Foi assim com Tucuruí e com as usinas do (rio) Madeira. Paulatinamente, as críticas desaparecem. Mas quero dizer que incorporamos ao projeto todas as críticas construtivas visando o desenvolvimento sustentável. Não tenho dúvida de que o Brasil não teve projeto mais estudado que Belo Monte. Usamos os melhores quadros do país. Quando a racionalidade imperar, o país vai ver o quanto perdeu por não ter feito Belo Monte antes.

O Ibama concedeu ao projeto uma licença inédita, que só libera o canteiro.

MUNIZ: Não é inédito. Aconteceu o mesmo com as usinas do Madeira (Jirau e Santo Antônio). Essa licença foi concedida para não perdermos a janela hidrológica. Se as obras não começarem agora, rapidamente, o projeto vai atrasar um ano. Isso tem um custo imenso para o país. 
O Ibama foi pressionado?

MUNIZ: Isso eu prefiro não responder. (OLIVEIRA, 2011)

Assim, como é possível constatar, muitas foram as controvérsias no que diz respeito a execução do projeto, que em geral polarizaram dois discursos. Aquele empenhado em dar início ao projeto, na perspectiva de catalisar o desenvolvimento local e nacional, levando em conta o incremento na produção de energia e demais fatores econômicos. Este discurso em geral aborda o desenvolvimento pautado na perspectiva econômica anteriormente aludida.

Já o outro concernido com as repercussões ambientas de tamanha intervenção na região amazônica, bem como o prejuízo tanto para as comunidades ribeirinhas, quanto para as populações indígenas que habitam a área. Para essa abordagem, o desenvolvimento é concebido a partir dos seus altos custos humanos e ambientais, acepção socioambientalista, que tende a refutar os intuitos que associam esse conceito ao progresso.

É com base nestas duas abordagens que os discursos se estruturam, sendo identificada também uma terceira forma de tratar a questão, que apesar de aparentar ser uma solução plausível, guarda artifícios retóricos estratégicos para promover aceitação. Situação em que se constata a utilização do conceito de "desenvolvimento sustentável" como forma de garantir o consenso, pois o discurso estratégico vale-se da ampla adesão que o termo possui, sem que exista efetivamente a sustentabilidade do projeto defendido.

Aliás, essa forma estratégica de manejar o termo não é prerrogativa das autoridades brasileiras, em razão da formação de um senso comum em escala global a respeito da importância do desenvolvimento sustentável para a sociedade, esse processo de mascarar todo tipo de ação como sendo sustentável - ou verde -, ainda que não seja, é denominado de "greenwashing”.

Geralmente associado a empresas, que se valem de campanhas publicitárias aparentando ter reformulado suas formas de atuação original para um modelo sustentável, que corresponde ao greening, ou seja, um "enverdamento", que consiste na própria preocupação com as questões socioambientais. A mudança, no entanto, é meramente aparente, e não passa, conforme a definição do Greenpeace, de um discurso "cynical, superficial, public relations marketing aimed at projecting a falsely benign environmental corporate image" (NAJAM, 2011, p.74).

Dessa forma, a relevância de identificar outros relatos, como o do MPF e das comunidades afetadas, reside justamente na proposta retórica analítica, na medida em que por 
meio dessas outras versões dos fatos, passa a ser possível agregar maior complexidade ao reducionismo operado por certas matrizes teóricas. Para tanto, foi preciso confrontar o discurso das autoridades em questão com as ações propostas pelo MPF, que em contrapartida destaca que o desenvolvimento proposto tem trazido diversas consequências para as populações ribeirinhas e indígenas. Havendo, inclusive, provimentos jurisdicionais reconhecendo o dano a estes grupos, bem como posicionamentos de órgãos internacionais no mesmo sentido.

Nesse sentido, a análise do discurso e a permanência dos mesmos elementos de legitimação ao longo do tempo permitem identificar a manutenção de uma pretensão desenvolvimentista, que ressoa, mesmo no cenário democrático, a mesma forma de manejar os recursos naturais da Amazônia do período ditatorial militar. Essa continuidade em muito auxilia a compreender as dificuldades para implementar a proposta constitucional em relação a proteção do meio ambiente. Ao passo que o paradigma desenvolvimentista irrefreado que privilegia unilateralmente as questões econômicas, colide frontalmente com a principiologia constitucional, que parte de pressupostos como a observância do procedimento do licenciamento ambiental, a fim de considerar as comunidades afetadas por intermédio de consultas e audiências públicas compatibilizando desenvolvimento com o respeito aos direitos fundamentais.

\section{CONSIDERAÇÕES FINAIS}

A retórica relaciona-se com a postura que concebe a história de forma sisífica, na medida em que "como Sísifo não sabe até onde, montanha acima, conseguirá transportar a pedra, a humanidade não sabe aonde vai chegar" (ADEODATO, 2007, p.266), sendo que cada momento histórico guarda nova particularidade, que não pode ser meramente compreendida somente a partir de um retrospecto para análise do passado. Nesse sentido, a pretensão retórica não se vincula a concepções etiológicas ou escatológicas da história, ao passo que não compreende esta como uma sucessão causal de fatos incrementados por efeitos, que entre si estabelecem um nexo. A relevância desta observação verifica-se justamente em função do componente cético que dela deriva, essencial para a compreensão do termo “desenvolvimento", escopo desta análise.

Isso porque, se cada circunstância histórica carrega consigo a novidade de fatos 
irrepetíveis, é necessário reconhecer a impossibilidade de compreender de forma definitiva qualquer coisa que se processe na história, na medida em que "o que é humano modifica-se ao longo da história e isso só pode ser compreendido sob perspectiva relativa às preferências dos participantes, aos consensos linguísticos, às capacidades de causar dano ao outro, de distribuir vantagens, em sumo, ao ambiente da comunicação. É a partir dessa contribuição que se pretendeu estruturar a abordagem do termo "desenvolvimento", enquanto um conceito sempre inacabado, sujeito a constantes reformulações e traduções ao longo do tempo, o que acarreta, inclusive, em possíveis contradições dos diferentes relatos possíveis capitaneados por diversas matrizes teóricas.

Na contramão dessa constatação, discursos de autoridades e instituições que atuaram durante o processo de licenciamento ambiental da usina de Belo Monte, estrategicamente, lançam mão do termo desenvolvimento para legitimar seus respectivos posicionamentos, como se esta palavra possuísse um sentido uno, atribuído por um relato correto, neutro e sempre aliada a uma carga axiológica positiva. Assim, tais pronunciamentos adotam uma proposta ditada pela retórica prática ou estratégica, a fim de influenciar a compreensão desse termo, com vistas a erigi-lo em objeto, ou seja, fatos relativamente fixados, "aos quais alguns relatos selecionados aderem, em detrimento de outros, transformando relatos de opiniões em objetos, que supostamente constituem as definições da linguagem de controle instituída, os relatos corretos, a verdade"(ADEODATO, 2008, p.73).

É como se a palavra desenvolvimento carregasse consigo único sentido possível, engessado e definitivo, atribuído de forma linear durante a experiência histórica, quando na verdade, enquanto conceito multidimensional, o desenvolvimento pode ser lido a partir de várias matrizes teóricas, conforme exposto em capítulo específico. Além disso, o que se observa é a utilização do conceito de desenvolvimento sustentável sem que haja a preocupação efetiva com a relação desta proposta com os fatos verificados durante o processo de execução da usina de Belo Monte. Assim, ao que parece, como pode ser verificado nos discursos destacados é a utilização estratégica do conceito para obter ampla aceita e legitimar as atividades em andamento, as quais continuam pautando-se pelas bases desenvolvimentistas que privilegia a acepção econômica.

Mediante este artifício retórico esse discurso, que já não agrega tanto consenso em razão da própria conjuntura global, é travestido pelo ornamento da sustentabilidade, sendo que este conceito funciona exatamente como uma ornamentação, sem maiores verificações 
das repercussões nada sustentáveis do projeto defendida. O contraponto aos discursos de algumas autoridades ressalta a importância de uma análise complexa da questão, que considere não só o relato dominante, mas também os relatos vencidos. Isso porque, esse exercício analítico pode evidenciar, inclusive, a manutenção de um discurso vencedor herdado de um regime ditatorial, o que sem dúvida fornece proeminente substrato para compreender a razão de tantas crises e rupturas no que diz respeito a questão ambiental no Brasil, principalmente no tocante a região da Amazônia.

A dificuldade de implementação do projeto constitucional de proteção ao meio ambiente, voltado para o fito de compatibilizar o manejo de recursos e a observância dos direitos fundamentais, ao que parece, em muito se relaciona com a herança desenvolvimentista que privilegia a questão econômica amplamente implementado pelo regime militar. Continuar tratando a Amazônia como um espaço vazio para a execução de projetos de toda ordem certamente contraria as bases constitucionais democráticas e a crise dessa proposta se instala, principalmente, quando o método de atuação vale-se de institutos jurídicos como a "licença prévia de instalação", que sequer encontra previsão no ordenamento jurídico. $\mathrm{O}$ aviso de incêndio que anuncia a crise, parte da constatação de que o modelo anterior continua a ditar a forma de manejo da região amazônica, inclusive valendo-se de exceções legais, que também utilizava no passado, para viabilizar sua proposta desenvolvimentista.

Crise, é certamente um vocábulo que reincide nos ensaios e reflexões filosóficas. Tanto por isso, durante o encarceramento na prisão de Turi, na Itália, Antonio Gramsci ponderou em suas anotações, que: "a crise consiste precisamente no fato de que o velho está morrendo e o novo não pode nascer; neste interregno, surge uma grande variedade de sintomas mórbidos" (GRAMISCI, 1971, p.25-26). A usina hidroelétrica de Belo Monte pode ser compreendida, a partir das palavras de Gramsci, como um dos sintomas mórbidos que assombram o período democrático pós-Constituição de 1988. Isso porque, se a Constituição representa a ascensão do novo, que emerge na ambição de fazer cessar a crise, sepultando definitivamente o velho regime ditatorial militar, certamente a manutenção, já no período democrático, de um dos maiores projetos da ditatura, bem como da racionalidade que o orienta, só evidencia o quão resiliente este velho ainda pode ser ou quão atual ainda é a crise. 


\section{REFERÊNCIAS}

ADEODATO, João Maurício. Filosofia do direito: uma crítica à verdade na ética e na ciência. 3.ed.rev.ampl.São Paulo: Saraiva, 2005.

João Maurício. Ética e retórica: para uma teoria da dogmática jurídica. 3.ed. rev.e ampl. São Paulo: Saraiva, 2007.

João Maurício. Retórica como metódica para estudo do direito. Revista Sequência, n. 56, jun. 2008.

ALMEIDA, Argus Vasconcelos de; FALCAO, Jorge Tarcisio da Rocha. A estrutura histórico-conceitual dos programas de pesquisa de Darwin e Lamarck e sua transposição para o ambiente escolar. Ciênc. educ., Bauru, v. 11, n. 1, p. 17-32, Apr. 2005.

ANTONAZ, Diana. Os estudos sócio-antropológicos no EIA da UHE de Belo Monte. In: MAGALHÃES, S. M. S. Barbosa; HERNANDEZ, F. (org.). Análise Crítica do Estudo de Impacto Ambiental da UHE Belo Monte. Belém, 29 de outubro de 2009. Press, 1987.

ARNT, H. W. Economic Development: The History of an Idea. Chicago: University

ARRIGHI, Giovanni. A ilusão do desenvolvimento. 6.ed. Petrópolis: Editora Vozes, 1998.

BALDINGER, Kurt. L'étymologie, hier et aujourd'hui. Cahiers de l'Association internationale des études francaises. v.11, n.1, 2001.

BBC BRASIL. OEA pede que Brasil suspenda Belo Monte, e governo se diz 'perplexo'. Brasília, 05 abr. 2011. 
BENJAMIN, Antonio Herman. Estudo prévio de impacto ambiental. São Paulo: RT, 1993.

BLANC, Marcel. Os herdeiros de Darwin. São Paulo: Scritta, 1994.

BONIN, R. Patriota critica pedidos da OEA sobre usina de Belo Monte: organização pediu fim da obra da usina hidrelétrica de Belo Monte: ministro disse que atitude da OEA desestimula políticas para os índios. Globo.com, 06 abr. 2011.

BRASIL. Plano plurianual 2004-2007: orientação estratégica de governo um Brasil para todos: crescimento sustentável, emprego e inclusão social. Brasília, 2004.

BUCKHARDT JR., R. W. Lamarck, evolution, and polictics of science. Journal of the History of Biology, Dordrecht, n. 3, 1970.

CARROLL, Lewis. Alice no País das Maravilhas. Porto Alegre: L\&PM, 2014.

DÜRING, Ingemar. Aristóteles. Exposición e interpretación de su pensamento. México: Universidad Nacional Autónoma de México, 1990.

ECO, Umberto. Os limites da interpretação. São Paulo: Perspectiva, 2004.

FLEURY, Lorena Cândido; ALMEIDA, Jalcione. A construção da Usina Hidrelétrica de Belo Monte: conflito ambiental e o dilema do desenvolvimento. Ambiente e sociedade, São Paulo, 2013, v. 16, n. 4.

FONTES, C. O compromisso do PT com os povos indígenas. Instituto Socioambiental, São Paulo, abr. 2003. Disponível em: www.socioambiental.org/esp/mesdoindio/politca. shtm. Acesso em: fev. 2020.

GRAMISCI, Antônio. Cadernos: seleção de notas de prisão. Rio de Janeiro: Paz e Terra, 1971.

INSTITUTO SOCIOAMBIENTAL. Especial Belo Monte: cronologia histórica: cronologia do projeto. Manchetes Socioambientais, São Paulo, 2012.

JATOWT, Adam; DUH, Kevin. A framework for analyzing semantic change of words across time. Joint Conference on Digital Libraries (JCDL 14th). London: IEEE Press Piscataway, 2014.

MARX, Karl; ENGELS, Friedrich. The Communist Manifesto. Londres: Penguin Books, 1998.

MILARÉ, Édis; BENJAMIN, Antonio Herman. Estudo prévio de impacto ambiental. São Paulo: RT, 1993. 
MORETTO, E. M. Histórico, tendências e perspectivas no planejamento espacial de usinas hidrelétricas brasileiras: a antiga e atual fronteira Amazônica. Ambiente \& Sociedade, São Paulo, v.15, n.3, set./dez. 2012.

NASAR, Sylvia. A imaginação econômica: gênios que criaram a economia moderna e mudaram a história. São Paulo: Companhia das Letras, 2012.

OLIVEIRA, Flávia. Entrevista com José Antônio Luiz Lopes: O país perdeu por não ter feito Belo Monte antes. Estado de São Paulo. São Paulo, 29 de janeiro de 2011.

OST, François. A natureza a margem da lei: a ecologia a prova do Direito. Lisboa: Instituto Piaget, 1995.

PERELMAN, Chaïm. Lógica jurídica. Nova retórica. São Paulo: Martins Fontes, 1998.

SCHUMPETER, J. A. The Theory of Economic Development. Cambridge: Harvard University Press, 1989.

SEN, Amartya. Desenvolvimento como liberdade. São Paulo: Companhia das Letras, 2010.

SILVA, L. I. da. Carta ao povo brasileiro. São Paulo, 22 jun. 2002. Disponível em: ://www. iisg.nl/collections/carta_ao_povo_brasileiro.pdf . Acesso em: fev. 2017.

THÉRY, H. Situações da Amazônia no Brasil e no continente. Estudos Avançados, São Paulo, v.19, n.53, 2011. 